\title{
Effect of the Immunoglobulin G-A-M Treatment on Hepatic Functions and Mortality rates in Patients with Septic Shock
}

\author{
Ahmet Bindal'(i), Lütfi Yavuz'(i) \\ 1 Şanlıurfa Education and Research Hospital, Departmant of Adult Intensive Care Unit, Şanlıurfa, Turkey \\ 2 University of Health Sciences, Antalya Education and Research Hospital, Departmant of Adult İntensive Care Unit, Antalya, Turkey
}

\begin{abstract}
Background: In this study, we aimed to explore the effects of conventional sepsis treatment, including classical antibiotherapy and Immunoglubin (Ig) G-A-M combination (Pentaglobin ${ }^{\circledR}$ ), on liver function tests and mortality rate in patients with septic shock.

Methods: All patients diagnosed with septic shock and treated with Pentaglobin ${ }^{\circledR}$ in the adult intensive care unit of Suleyman Demirel University Practice and Research Hospital between 2005-2013 were retrospectively examined. Demographic properties, age, gender, intensive care treatment duration, general exitus day, the death rate in the first 28 days, general death-survival period, 28th-day death rate, mortality rate, and diagnosis of cases were recorded.

Results: At the end of the treatment, it was found that 35 of the cases died, and 35 were transferred to various clinical wards. The overall mortality rate was calculated as $50 \%$ from the obtained data. It was found that 40 patients survived in the first 28 days while 30 patients died. In this study, it was observed that Pentaglobin ${ }^{\circledR}$ treatment had no statistically significant impact on ASTALT- Albumin values and mortality rates.

Conclusions: However, early diagnosis of sepsis, early initiation of antibiothearpy, early source control, and timely initiation of appropriate fluid therapy play a key role in the succsess of sepsis treatment. For this purpose, as emphasized in the sepsis 3 guideline, we think that raising awareness by physicians and practitioners in the early diagnosis of sepsis is the most important step in the treatment of this clinical condition.
\end{abstract}

Keywords: Sepsis, Liver Function Tests, Immunoglobulin G-A-M.

\section{INTRODUCTION}

Sepsis is a life-threatening organ dysfunction caused by the host response to dysregulated host response to infection (1). It is still a clinical manifestation with high mortality, despite the pathophysiology of the disease being better defined in recent years, advances in antimicrobial treatment, diagnostic methods, and advances in technology (2). With the development of advanced diagnosis and treatment methods, the early mortality rates of patients hospitalized in intensive care units due to massive bleeding, major trauma, cardiogenic shock, and necrotizing pancreatitis are decreasing (3-6). However, while the follow-up and treatment of these patients continue, the prolongation of the length of stay 
in the intensive care unit may increase the mortality rate of these patients due to sepsis-septic shock-related multiorgan failure (7).

Septic shock is a subset of sepsis with circulatory and cellular/metabolic dysfunction associated with a higher risk of mortality. Patients with septic shock can be identified with a clinical construct of sepsis with persisting hypotension requiring vasopressors to maintain Mean Arterial Pressure (MAP) $\geq 65 \mathrm{mmHg}$ and having a serum lactate level $>2 \mathrm{mmol} / \mathrm{L}$ despite adequate volume resuscitation. With these criteria, hospital mortality is in excess of $40 \%$ (1).

Sepsis and septic shock occur at a rate of $10.5-40 \%$ in intensive care patients $(8,9)$, and although there has been a severe decrease of mortality rates in recent years, it is still high, ranging from $18-75 \%$ (8-10). In the point prevalence survey conducted by Baykara et al. (11) in our country, the prevalence of sepsis and septic shock in intensive care was $38.8 \%$, and the mortality rate in sepsis and septic shock was $55.7 \%$ and $70.4 \%$, respectively.

There have been studies reporting that the addition of intravenous immunoglobulins to treatment in severe sepsis positively affects mortality (12). The effects of intravenous immunoglobulins are activating leukocytes, increasing bactericidal activity in serum, inhibiting cytokine effects, and regulating the complement system (13-15).

The liver, also the target organ, plays a crucial role in sepsis pathology. Two primary mechanisms explain this dual role of the liver. The first is liver blood supply, which takes $25 \%$ of the total cardiac output. The portal blood flow providing this blood supply originates from the splenomesenteric area, which is the most affected vascular area by vasoconstriction and bacterial translocation in sepsis. The second is the heterogeneous cellular structure of the liver consisting of Kupfer cells, hepatocytes, and sinusoidal endothelial cells. All of these cells have immune, anti-infectious and metabolic roles. In this study, we aimed to investigate the effect of conventional sepsis treatment, including classical antibiotherapy and Pentaglobin ${ }^{\circledR}$, on liver function tests in severe sepsis patients.

\section{MATERIALS AND METHODS}

The current study was approved by Suleyman Demirel University Medical Faculty Hospital Local Ethics Committee (Date: 31.07.2013, No: 172). This study was performed according to the ethical standards laid down Declaration of Helsinki and its later amendments. All cases diagnosed with severe sepsis and treated with the combination of Pentaglobin ${ }^{\circledR}$ between 2005 and 2013 in the adult intensive care unit of Suleyman Demirel University Research and Training Hospital were screened. The records of the patients in the hospital and intensive care unit were extracted from the electronic database and the archived files and were analyzed retrospectively.

\section{Study design and patients}

Demographic characteristics of the cases, age, gender, diagnosis, duration of stay in intensive care, exitus day, rate of death-survival in the first 28 days, rate of death-survival, $28^{\text {th }}$-day death rate, and mortality rate were recorded. Patients with positive reproduction of pathogenic microorganisms in blood culture, patients aged 18 years and over, patients with APACHE II score of 25 and above, and patients with severe sepsis (Body Temperature (BT) of $>38{ }^{\circ} \mathrm{C}$ or $<36{ }^{\circ} \mathrm{C}$, Heart Rate (HR) of $>90 /$ min, Respiratory Rate (RR) of $>20 /$ min or $\mathrm{PaCO}_{2}<32$ $\mathrm{mmHg}$, leukocyte count $>12000 / \mathrm{mm}^{3}$ or $<4000 / \mathrm{mm}^{3}$ ) were included in the study. Patients with a diagnosis of chronic liver failure and those who did not complete the 3-day treatment period were excluded from the study.

\section{Data}

In our clinic, the Pentaglobin ${ }^{\circledR}$ is administered with a daily infusion dose of $5 \mathrm{mg} / \mathrm{kg}$ in 12 hours for a total of 3 days. Data from 2 different periods were collected and recorded to measure the effectiveness of the treatment. These periods were named "Pre-Treatment Period" (AST 1, ALT 1, Albumin 1) and "Post-Treatment Period" (AST 2, ALT 2, Albumin 2). The pre-treatment period was considered the period in which the diagnosis was made, and treatment was initiated. The post-treatment period was considered as 24 hours after the termination of the Pentaglobin $®$ infusion, in other words, 96 hours after the initiation of the Pentaglobin ${ }^{\circledR}$ therapy.

\section{Statistical Analysis}

"SPSS for windows 15.0" Statistical Package Program was used for statistical analysis of the collected data. Wilcoxon Signed Ranks test was used to compare demographic data and AST-ALT-Albumin values before and after Pentaglobin $\AA$. Results were submitted as Mean \pm Standard Deviation (SD), median (minimum-maximum). The p-value of $<0.05$ was considered significant. 


\section{RESULTS}

A total of 82 patients received Pentaglobin ${ }^{\circledR}$ therapy. Since 2 cases were diagnosed with chronic liver failure, and 10 cases could not complete the 3-day Pentaglobin ${ }^{\circledR}$ infusion treatment period, 12 patients were excluded. A total of 70 patients who met the study criteria were included in the study. The mean age of the patients was $59.10 \pm 20.29$ years. 19 of the cases were female $(27.2 \%)$, 51 were male $(72.8 \%)$.

At the end of the treatment, it was found that 35 of the cases died, and 35 were transferred to various clinical wards. The overall mortality rate was calculated as $50 \%$ from the obtained data. It was found that 40 patients survived in the first 28 days while 30 patients died. The mortality rate in the first 28 days was calculated as $42.85 \%$. The overall mortality rate of male patients was $47 \%$ (n: 24$)$, and the first 28-day mortality rate was $37 \%$ (n: 19). While the overall mortality rate of female patients was $57 \%$ (n: 11), all of the female patients died within the first 28 days. The duration of the adult intensive care unit stay was $44.21 \pm 49.82$ days. The mean day of death was $16.14 \pm 18.80$ days, while the shortest period was six days, and the longest was 363 days.

Of the 70 cases included in the study, 37 patients were in sepsis due to pneumonia, 18 were due to after elective post-operative surgery, eight were due to posttrauma, three were due to emergency post-operative surgery, two were due to syndromes such as Guillain Barre, HELLP, and two were due to acute poisoning.

Before Pentaglobin ${ }^{\circledR}$ treatment, the minimum AST value of the patients was $2 \mathrm{IU} / \mathrm{L}$, while the maximum value was $1296 \mathrm{IU} / \mathrm{L}$, the median value was $36 \mathrm{IU} / \mathrm{L}$, the mean value was $98.32 \pm 229.40 \mathrm{IU} / \mathrm{L}$. After treatment, the minimum AST value was $2 \mathrm{IU} / \mathrm{L}$; the maximum value was $873 \mathrm{IU} / \mathrm{L}$, the median value was $34 \mathrm{IU} / \mathrm{L}$, the mean value was $91.80 \pm 151.29 \mathrm{IU} / \mathrm{L}$. Changes in AST values before and after treatment were statistically insignificant (p: 0.842). Before Pentaglobin ${ }^{\circledR}$ treatment, the minimum ALT value of the patients was $2 \mathrm{IU} / \mathrm{L}$; the maximum value was $1037 \mathrm{IU} / \mathrm{L}$, the median value was $30 \mathrm{IU} / \mathrm{L}$, the mean value was $72.94 \pm 154.42 \mathrm{IU} / \mathrm{L}$, while the minimum value after treatment was $4 \mathrm{IU} / \mathrm{L}$, the maximum value was 958 $\mathrm{IU} / \mathrm{L}$, the median value was $26 \mathrm{IU} / \mathrm{L}$, the mean value was 74.91 $\pm 140.46 \mathrm{IU} / \mathrm{L}$. Changes in ALT values before and after treatment were statistically insignificant (p: 0.649). Before Pentaglobin ${ }^{\circledR}$ treatment, the minimum albumin value of the patients was $1,51 \mathrm{gr} / \mathrm{dL}$; the maximum value was $4.1 \mathrm{gr} / \mathrm{dL}$, the median value was $2.75 \mathrm{gr} / \mathrm{dL}$, the mean value was $2.75 \pm 0.55 \mathrm{gr} / \mathrm{dL}$, while the minimum value after treatment was $1.52 \mathrm{gr} / \mathrm{dL}$, the maximum value was $4.26 \mathrm{gr} / \mathrm{dL}$, the median value was $2.62 \mathrm{gr} / \mathrm{dL}$, the mean value was $2.70 \pm 0.56 \mathrm{gr} / \mathrm{dL}$. Changes in Albumin values before and after treatment were statistically insignificant (p: 0.346).

\section{DISCUSSION}

Sepsis is a life-threatening condition that occurs with the impaired response of the body to the invasion after the passage of microorganisms or toxins into normally sterile tissues and blood, in other words, after the development of infection (16). The process initiated by microorganisms or their toxins can lead to multi-organ damage and multi-organ failure caused by dysregulated host response. Hemostatic imbalance, which develops in the clinical course of sepsis, plays an important role in increasing endothelial dysfunction, organ and tissue damage, and aggravating the clinical manifestation, and is characterized by impaired intracellular homeostasis. Cell hypoxia and apoptosis, in other words, programmed cell death, are responsible for organ dysfunctions and death in sepsis (17).

The liver, on the one hand, provides the clearance and detoxification of the bacteria that cause sepsis, endotoxins, and vasoactive substances formed during sepsis; on the other hand, it regulates the activities of the cells involved in the host defense. The liver is both a source of inflammatory mediators and the target organ affected by these mediators. One of the main reasons for this dual role is that the liver uses approximately $25 \%$ of the total blood flow. Most of the blood supply of the liver is provided by the portal vein system. This splenomesenteric region is the most vascular area affected by vasoconstriction - vasodilation and bacterial translocation in sepsis. The second reason is that the liver consists of very heterogeneous cell groups. Almost all of these cells have immune, anti-infectious and metabolic roles.

The properties of intravenous immunoglobulins, such as increasing the bactericidal serum activity, stimulating leukocytes, neutralizing bacterial endotoxins and exotoxins, and regulating complement activity, suggest that these agents in sepsis may be used in sepsis be beneficial. In the study conducted by McCuskey et al. (18) on sepsismodeled rats, it was reported that the microvascular changes in sepsis were minimized, leukocyte adhesion 
was decreased, and the number of perfused sinusoids increased with intravenous IgG administration. They also reported that the increase in plasma endotoxin level and decrease in endotoxin neutralization capacity observed in septic rats changed the least in rats that were administered intravenous immunoglobulin. Again, in the study conducted by Shmygalev et al. (19), it was found that phagocytic activity was increased in polymorphonuclear leukocytes in rabbits with endotoxemia with $\mathrm{Ig} M$ administration, and liver energy stores were higher than in control groups.

In our study, although there was an arithmetic decrease in AST value in the post-treatment period compared to pre-treatment, this decrease was not considered statistically significant (p: 0.842). Although there was an arithmetic increase in ALT value in the post-treatment period compared to pre-treatment, this increase was not statistically significant (p: 0.649). There was an arithmetic decrease in albumin value in the post-treatment period compared to pre-treatment, which was not statistically significant (p: 0.346).

Alejandria et al. (20) reported that the mortality rate was significantly lower in patients given polyclonal immunoglobulin than patients given placebo or monoclonal immunoglobulin. The meta-analysis conducted by Kreymann et al. (21) in 2202 patients reported a significant reduction in mortality rates with Pentaglobin ${ }^{\circledR}$.

Pilz et al. (22) reported that the APACHE II score decreased in the group treated with intravenous immunoglobulin and that intravenous immunoglobulin treatment improved disease prognosis.

Reith et al. (23) in their study, patients who developed an intra-abdominal infection after surgery, were divided into two groups, and they applied Pentaglobin ${ }^{\circledR}$ and albumin treatment, respectively. In the group given Pentaglobin ${ }^{\circledR}$; observed that procalcitonin level decreased, clinical symptoms improved, shortened hospital stay, decreased APACHE II score, decreased endotoxin, TNF- $\alpha$, IL-8, IL10 levels.

In a controlled study by Özcan et al. (24) sepsis model was created in 48 rats via cecal ligation, and behavioral deficiencies and functions were examined. It was observed that these dysfunctions started to improve in the early period in rats using intravenous immunoglobulin.
In a research article published by Abroun et al. (25), they stated that the early use of Ig solutions enriched with immunoglobulin $\mathrm{M}$ at high doses for at least five days in critical patients with severe infections improved the results in these patients.

The microcirculatory disorder that develops during the clinical course of sepsis causes organ dysfunction by disrupting tissue oxygenation (26). A single-center, double-blind, randomized study conducted by Domizi et al. (27) revealed that sublingual microvascular perfusion was higher in patients using Pentaglobin ${ }^{\circledR}$.

Although the positive effects of intravenous immunoglobulin are mentioned in the studies conducted, it was stated in the sepsis survival guideline that the use of intravenous immunoglobulin did not provide any benefit in adult patients, especially in the light of recent studies (16).

In a meta-analysis by Cui et al. (28) examining published studies with a total of 1530 patients reported that mortality decreased in patients using Pentaglobin ${ }^{\circledR}$, but this low mortality was due to the low quality of the studies and insufficient evidence

In a study conducted by Tagami et al. (29), 4919 patients who developed sepsis after emergency laparotomy in a total of 845 hospitals were examined according to intravenous immunoglobulin treatment presence. They stated that the use of intravenous immunoglobulin did not make a significant difference in terms of mortality.

Again, in a multi-center controlled study conducted by Tagami et al. (30), 1014 hospitals and 8264 pneumo-sepsis patients were examined, and no difference was observed regarding mortality between patients who received immunoglobulin treatment compared to patients for whom it was not used. Similarly, Kadri et al. (31) examined 121 centers and 4127 patients with necrotizing fasciitis and did not observe any difference in mortality in patients receiving intravenous immunoglobulin.

Although the standard deviation was high and the sample size was small in our study, in line with our results, we think that the Pentaglobin ${ }^{\circledR}$ treatment used in sepsis patients has no positive effect on liver function tests.

In literature, there are many studies reporting the positive or negative effects of the use of immunoglobulin therapy in sepsis patients. We also did not see any positive effect 
of this treatment in our study. Although the antimicrobial, anti-infective, and immune-modulatory effects of this treatment are stated, we believe that this does not significantly benefit patient mortality.

While discussions continue about the effectiveness of advanced anti-infective treatment modalities, it is evident that sepsis mortality will decrease by early diagnosis of sepsis specified in the sepsis 3 guideline, triage, rapid transfer to the relevant unit, and initiation of treatment without delay $(1,32)$. In our study, the point we want to highlight is that this clinical situation, which still has such high mortality, should be noticed by the clinicians in the early period, and the treatment should be initiated immediately.

\section{Declarations}

The authors received no financial support for the research and/or authorship of this article. There is no conflict of interest.

The current study was approved by Suleyman Demirel University Medical Faculty Hospital Local Ethics Committee (Date: 31.07.2013, No: 172). This study was performed according to the ethical standards laid down Declaration of Helsinki and its later amendments.

\section{REFERENCES}

1. Singer M, Deutschman CS, Seymour CW, Shankar-Hari M, Annane D, Bauer M, et al. The Third International Consensus Definitions for Sepsis and Septic Shock (Sepsis-3). JAMA. 2016;315(8):801-10.

2. Gyawali B, Ramakrishna K, Dhamoon AS. Sepsis: The evolution in definition, pathophysiology, and management. SAGE Open Med. 2019;7:2050312119835043.

3. Bugiantella W, Rondelli F, Boni M, Stella P, Polistena A, Sanguinetti A, et al. Necrotizing pancreatitis: A review of the interventions. Int J Surg. 2016;28 Suppl 1:S163-71.

4. Eastridge BJ, Holcomb JB, Shackelford S. Outcomes of traumatic hemorrhagic shock and the epidemiology of preventable death from injury. Transfusion. 2019;59(S2):1423-1428.

5. van Breugel JMM, Niemeyer MJS, Houwert RM, Groenwold RHH, Leenen LPH, van Wessem KJP. Global changes in mortality rates in polytrauma patients admitted to the ICU-a systematic review. World J Emerg Surg. 2020;15(1):55.

6. Webb JG, Sanborn TA, Sleeper LA, Carere RG, Buller CE, Slater JN, et al. SHOCK Investigators. Percutaneous coronary intervention for cardiogenic shock in the SHOCK Trial Registry. Am Heart J. 2001;141(6):964-70.

7. Rodríguez-Acelas AL, de Abreu Almeida M, Engelman B, CañonMontañez W. Risk factors for health care-associated infection in hospitalized adults: Systematic review and meta-analysis. Am J Infect Control. 2017;45(12):e149-e156.
8. SepNet Critical Care Trials Group. Incidence of severe sepsis and septic shock in German intensive care units: the prospective, multicentre INSEP study. Intensive Care Med. 2016;42(12):1980-1989.

9. Karlsson S, Varpula M, Ruokonen E, Pettilä V, Parviainen I, Ala-Kokko $\mathrm{TI}$, et al. Incidence, treatment, and outcome of severe sepsis in ICUtreated adults in Finland: the Finnsepsis study. Intensive Care Med. 2007;33(3):435-43

10. Kaukonen KM, Bailey M, Suzuki S, Pilcher D, Bellomo R. Mortality related to severe sepsis and septic shock among critically ill patients in Australia and New Zealand, 2000-2012. JAMA. 2014;311(13):1308-16.

11. Baykara N, Akalin H, Arslantas MK, Hanci V, Caglayan C, Kahveci F, et al. Sepsis Study Group. Epidemiology of sepsis in intensive care units in Turkey: a multicenter, point-prevalence study. Crit Care. 2018 Apr 16;22(1):93.

12. RodrÃguez A, Rello J, Neira J, Maskin B, Ceraso D, Vasta L, et al. Effects of high-dose of intravenous immunoglobulin and antibiotics on survival for severe sepsis undergoing surgery. Shock. 2005;23(4):298304.

13. Basyreva LY, Brodsky IB, Gusev AA, Zhapparova ON, Mikhalchik EV, Gusev SA, et al. The effect of Intravenous Immunoglobulin (IVIG) on \textit\{ex vivo\} activation of human leukocytes. Hum Antibodies. 2016;24(3-4):39-44

14. Kaveri SV. Mechanisms of action of intravenous immunoglobulins. Bull Acad Natl Med. 2012;196(1):39-47; discussion 47-8. French.

15. Nakae T, Tanaka J, Nakano A, Ono Y. Complement-mediated bactericidal effect of antibodies in human intravenous preparation against multi-drug resistant pseudomonas aeruginosa. Jpn J Antibiot. 2008;61(6):379-87.

16. Rhodes A, Evans LE, Alhazzani W, Levy MM, Antonelli M, Ferrer $\mathrm{R}$, et al. Surviving Sepsis Campaign: International Guidelines for Management of Sepsis and Septic Shock: 2016. Intensive Care Med. 2017;43(3):304-377.

17. Hattori $\mathrm{Y}$, Takano $\mathrm{K}$, Teramae $\mathrm{H}$, Yamamoto S, Yokoo H, Matsuda N Insights into sepsis therapeutic design based on the apoptotic death pathway. J Pharmacol Sci. 2010;114(4):354-65.

18. McCuskey RS, Nishida J, McDonnell D, Baker GL, Urbaschek R, Urbaschek B. Effect of immunoglobulin $\mathrm{G}$ on the hepatic microvascular inflammatory response during sepsis. Shock. 1996;5(1):28-33.

19. Shmygalev S, Damm M, Knels L, Strassburg A, WÃ¹/4nsche K, Dumke $\mathrm{R}$, et al. IgM-enriched solution BT086 improves host defense capacity and energy store preservation in a rabbit model of endotoxemia. Acta Anaesthesiol Scand. 2016;60(4):502-12.

20. Alejandria MM, Lansang MA, Dans LF, Mantaring JB 3rd. Intravenous immunoglobulin for treating sepsis, severe sepsis and septic shock. Cochrane Database Syst Rev. 2013;2013(9):CD001090.

21. Kreymann KG, de Heer G, Nierhaus A, Kluge S. Use of polyclonal immunoglobulins as adjunctive therapy for sepsis or septic shock. Crit Care Med. 2007;35(12):2677-85.

22. Pilz G, Kreuzer E, Kääb S, Appel R, Werdan K. Early sepsis treatment with immunoglobulins after cardiac surgery in score-identified highrisk patients. Chest. 1994;105(1):76-82.

23. Reith HB, Rauchschwalbe SK, Mittelk Ãथtter U, Engemann R, Thiede A, Arnold A, et al. IgM-enriched immunoglobulin (pentaglobin) positively influences the course of post-surgical intra-abdominal infections. Eur J Med Res. 2004;9(10):479-84.

24. Ozcan PE, Senturk E, Orhun G, Gumru S, Arican N, Orhan N, et al. Effects of intravenous immunoglobulin therapy on behavior deficits and functions in sepsis model. Ann Intensive Care. 2015;5(1):62. 
25. Aubron C, Berteau F, Sparrow RL. Intravenous immunoglobulin for adjunctive treatment of severe infections in ICUs. Curr Opin Crit Care. 2019;25(5):417-422.

26. Hoffman JN, Fertmann JM, Vollmar B, Laschke MW, Jauch KW, Menger MD. Immunoglobulin M-enriched human intravenous immunoglobulins reduce leukocyte-endothelial cell interactions and attenuate microvascular perfusion failure in normotensive endotoxemia. Shock. 2008;29(1):133-9.

27. Domizi R, Adrario E, Damiani E, Scorcella C, Carsetti A, Giaccaglia $\mathrm{P}$, et al. IgM-enriched immunoglobulins (Pentaglobin) may improve the microcirculation in sepsis: a pilot randomized trial. Ann Intensive Care. 2019;9(1):135.

28. Cui J, Wei X, Lv H, Li Y, Li P, Chen Z, et al. The clinical efficacy of intravenous IgM-enriched immunoglobulin (pentaglobin) in sepsis or septic shock: a meta-analysis with trial sequential analysis. Ann Intensive Care. 2019;9(1):27.

29. Tagami $T$, Matsui $H$, Fushimi $K$, Yasunaga $H$. Intravenous immunoglobulin use in septic shock patients after emergency laparotomy. J Infect. 2015;71(2):158-66.

30. Tagami $T$, Matsui $H$, Fushimi $K$, Yasunaga $H$. Intravenous immunoglobulin and mortality in pneumonia patients with septic shock: an observational nationwide study. Clin Infect Dis. 2015;61(3):385-92.

31. Kadri SS, Swihart BJ, Bonne SL, Hohmann SF, Hennessy LV, Louras $\mathrm{P}$, et al. Impact of Intravenous Immunoglobulin on Survival in Necrotizing Fasciitis With Vasopressor-Dependent Shock: A Propensity Score-Matched Analysis From 130 US Hospitals. Clin Infect Dis. 2017;64(7):877-885.

32. Gürü S, Kadı G, Öktem B, Karamercan MA. Carboxyhemoglobin, methemoglobin and lactate levels in patients with systemic inflammatory response syndrome. Arch Curr Med Res. 2021;2(2):80-87 